\title{
Abobrinha-de-moita: um novo hospedeiro de fitoplasma do grupo 16Srlll
}

\author{
Luciano A. Melo ${ }^{1}$, Ivan P. Bedendo ${ }^{1}$ \& Valdir A. Yuki ${ }^{2}$ \\ ${ }^{1}$ Departamento de Entomologia, Fitopatologia e Zoologia Agrícola, ESALQ, Universidade de São Paulo, 13418-900, \\ Piracicaba, SP, Brasil; ${ }^{2}$ Instituto Agronômico de Campinas - IAC, 13020-970, Campinas, SP, Brasil
}

Autor para correspondência: Ivan P. Bedendo, e-mail: ipbedend@esalq.usp.br

\begin{abstract}
RESUMO
Em um plantio comercial localizado no Vale do Ribeira, no estado de São Paulo, foram observadas plantas de abobrinha-de-moita (Cucurbita pepo L.) apresentando superbrotamento de ramos, malformação da parte aérea e folhas disformes e enrugadas. Através de PCR foi demonstrada a presença de fitoplasma associado aos tecidos doentes. Um fitoplasma do grupo 16SrIII foi identificado por PCR e pela análise de RFLP, conduzida com cinco enzimas de restrição. A presente comunicação se constitui no primeiro relato da presença de um fitoplasma do grupo 16SrIII em abobrinha-de-moita no Brasil.
\end{abstract}

Palavras-chaves: Mollicutes, Cucurbitaceae, Cucurbita pepo, RFLP.

\begin{abstract}
Summer squash: a new host of phytoplasm belonging to the 16SrIII group

In a commercial field located in the Vale do Ribeira, in the State of São Paulo, Brazil, plants of summer squash (Cucurbita pepo L.) exhibiting witches' broom and leaf deformation were observed. PCR assays demonstrated the presence of phytoplasma associated with diseased tissues. A phytoplasma belonging to the 16SrIII group was identified by PCR and RFLP analysis performed with five restriction enzymes. The present note is the first report of the presence of phytoplasma representative of the 16SrIII group in summer squash in Brazil.
\end{abstract}

Keywords: Mollicutes, Cucurbitaceae, Cucurbita pepo, RFLP.

Diversas espécies cultivadas, silvestres e daninhas, pertencentes à família Cucurbitaceae, são hospedeiras de fitoplasmas. Nas espécies desta família, os sintomas expressos por plantas doentes são do tipo clorose, diminuição no porte da planta, produção excessiva de ramos, esterilidade de flores, malformação de órgãos, redução da quantidade e qualidade dos frutos, ramos rígidos e eretos e folhas rígidas e espessas (Zitter et al., 1996). Esse quadro sintomatológico é genericamente conhecido por "amarelos".

$\mathrm{Na}$ década de cinqüenta, em campos localizados na Califórnia (USA), foi relatada a doença aster yellows, caracterizada pelos sintomas descritos, em plantas de moranga (Cucurbita maxima) e abobrinha-de-moita (Cucurbita pepo) (Freitag, 1956). Inicialmente a doença foi atribuída a vírus, porém, posteriormente, foi reconhecida como sendo associada a um fitoplasma pertencente ao grupo 16SrI (Lee et al., 1993; Zitter et al., 1996). Em diversas áreas da Austrália, foram observados sintomas de amarelos em plantas de abóbora ( $C$. maxima e $C$. moschata) infectadas por um fitoplasma do grupo 16SrXII (Streten et al., 2005).

Parte da Dissertação de Mestrado do primeiro autor. ESALQ, Universidade de São Paulo. Piracicaba SP. 2009.
No Brasil, a presença de fitoplasmas em abóbora da espécie C. moschata foi assinalada no estado do Rio de Janeiro em 2001 e a análise de plantas que apresentavam clorose, redução do limbo foliar e malformação de frutos permitiu identificar um fitoplasma do grupo $16 \mathrm{SrIII}$ associado à doença (Montano et al., 2006). A associação de fitoplasmas pertencentes a diferentes grupos $16 \mathrm{Sr}$ com diversas espécies de cucurbitáceas tem sido relatada. Fitoplasma pertencente ao grupo 16SrVIII foi encontrado em plantas de bucha (Luffa spp.) afetadas pelo superbrotamento, em Taiwan (Lee et al., 1993). Na Costa Rica, um fitoplasma do grupo $16 \mathrm{SrI}$ foi identificado em campos comercias de chuchu e de Sechium tacaco, bem como na planta daninha Rytidostylis carthaginensis (Villalobos et al., 2002). Foi relatada ainda a ocorrência de um fitoplasma do grupo 16SrXII em plantas infectadas de Cucumis myriocarpus Naud., na Austrália (Saqib et al., 2006). No Brasil, tem sido freqüente a ocorrência de fitoplasmas do grupo $16 \mathrm{SrIII}$ em cucurbitáceas, sendo estes fitopatógenos encontrados em associação com anomalias em chuchu, abóbora, bucha e melão-de-São Caetano (Montano et al., 2000, 2006, 2007a).

O presente trabalho foi conduzido em razão da ocorrência de plantas de abobrinha-de-moita apresentando 
típicos sintomas de amarelos, em plantio comercial localizado no Vale do Ribeira (SP), no ano de 2006. O objetivo foi detectar e identificar o fitoplasma, visando aumentar os conhecimentos sobre a distribuição e o círculo de hospedeiros deste agente patogênico.

As plantas de abobrinha-de-moita afetadas apresentavam superbrotamento de ramos, malformação da parte aérea e folhas disformes e enrugadas. A partir do material coletado no campo, foram obtidas amostras de DNA total, as quais foram usadas nos testes moleculares de PCR e RFLP. Plantas sadias, obtidas a partir de sementes comerciais, foram cultivadas em vasos e mantidas em casa de vegetação, sendo utilizadas como controle negativo.

Cada amostra de DNA foi obtida a partir de $0,2 \mathrm{~g}$ de tecido fresco do talo e das nervuras das folhas, localizados no terço inferior, médio e superior de planta sintomática, segundo o protocolo descrito por Ahrens \& Seemüller (1992). A detecção do fitoplasma foi feita através de PCR duplo, utilizando-se os "primers" P1/Tint (Smart et al., 1996) na primeira reação, seguido do par R16F2n/ R16R2 (Gundersen \& Lee, 1996) na segunda reação. Para identificação por PCR duplo foram empregados os pares P1/Tint e R16(III)F1/R16(III)R1 (Lee et al., 1994), para amplificação e re-amplificação, respectivamente, do 16SrDNA do fitoplasma detectado nos tecidos doentes. O último par de "primers" referido é específico para a deteç̧ão de fitoplasmas afiliados ao grupo 16SrIII. Todas as reações foram realizadas para um volume final de $25 \mu \mathrm{L}$ contendo $200 \mu \mathrm{M}$ de cada dNTP; $0,4 \mu \mathrm{M}$ de cada "primer"; 1 unidade de Taq polimerase (Promega) e 20 ng de DNA total usado como molde. Para todas as reações, os controles negativos foram representados pelo DNA de planta sadia de abobrinha-de-moita e água deionizada. Como controles positivos das reações, foram usados o DNA de planta de milho infectada com o fitoplasma do enfezamento vermelho do milho, para o PCR de detecção e, o DNA de planta de berinjela infectada pelo fitoplasma do enfezamento da berinjela (representante do grupo 16SrIII), para o PCR de identificação molecular. As reações de PCR com P1/Tint foram conduzidas em termociclador programado para 30 ciclos: desnaturação a $94^{\circ} \mathrm{C}$ por 1 minuto, anelamento a $56^{\circ} \mathrm{C}$ por 1 minuto e extensão a $72^{\circ} \mathrm{C}$ por 2 minutos. As reações com os "primers" R16F2n/R16R2 e R16(III)F1/ $\mathrm{R} 16$ (III)R1 foram realizadas em termociclador ajustado para as seguintes condições: desnaturação inicial a $94^{\circ} \mathrm{C}$, por 2 minutos, seguida por 35 ciclos de desnaturação a $94^{\circ} \mathrm{C}$, por 1 minuto, anelamento a $50^{\circ} \mathrm{C}$, por 2 minutos e, extensão a $72^{\circ} \mathrm{C}$, por 3 minutos, e uma etapa de extensão final a $72^{\circ} \mathrm{C}$, por 7 minutos. Uma alíquota de $5 \mu \mathrm{L}$ dos produtos de PCR de cada amostra foi aplicada em gel de agarose 1\%. Após a eletroforese, o gel foi corado com brometo de etídeo e as bandas de DNA foram visualizadas em transiluminador de luz ultravioleta. O marcador de peso molecular utilizado foi $1 \mathrm{~kb}$ DNA ladder (Invitrogen).

As seqüências amplificadas a partir do 16SrDNA do fitoplasma encontrado em abobrinha-de-moita, através de PCR duplo com os "primers" P1/Tint-R16F2n/R16R2, foram analisadas por RFLP com as enzimas de restrição AluI, RsaI, HpaII, HhaI e MboI. Alíquotas de $5 \mu \mathrm{L}$ de cada produto de PCR foram digeridas, separadamente, com cada uma das enzimas, a $36^{\circ} \mathrm{C}$, por um período de 30 horas. Os produtos da digestão foram analisados por eletroforese em gel de poliacrilamida 5\% corado com brometo de etídeo e, as bandas visualizadas em transiluminador de luz ultravioleta. $\mathrm{O}$ marcador de peso molecular utilizado foi o $\phi X 174$ RF DNA HaeIII digest (Invitrogen). Os perfis gerados foram confrontados com aqueles relatados na literatura e o fitoplasma identificado na abobrinha-de-moita foi classificado de acordo com os grupos descritos por Lee et al. (1998).

Através de PCR, usando os pares de "primers" P1/Tint e R16F2n/R16R2, fitoplasmas foram detectados em tecidos doentes pela amplificação de fragmentos genômicos de $1.200 \mathrm{pb}$, visualizados na forma de bandas nos géis de agarose. Fragmentos de 1.200 pb também foram amplificados nas reações que continham DNA de fitoplasma do enfezamento do milho, usado como controle positivo, porém não houve amplificações para os controles negativos, representados pelo DNA obtido de plantas sadias e amostras sem DNA. O PCR duplo conduzido com o pares P1/Tint e R16(III)F1/R16(III)R1 permitiu a identificação de um fitoplasma do grupo 16SrIII, pela amplificação de um fragmento genômico de 800 pb. Amplificações esperadas de $800 \mathrm{pb}$ também foram constatadas para o fitoplasma do enfezamento da berinjela, usado como controle positivo e sabidamente um representante do grupo 16SRIII.

A análise de RFLP mostrou que os padrões gerados para o fitoplasma identificado em quatro amostras de abobrinha-de-moita foram idênticos entre si, para cada uma das enzimas de restrição. Um representante do fitoplasma encontrado nas amostras foi selecionado e os seus padrões de RFLP estão apresentados na Figura 1. Os resultados também revelaram que os padrões obtidos para o fitoplasma da berinjela, usado como referência, foram idênticos àqueles encontrados para o fitoplasma da abobrinhade-moita, para todas as enzimas de restrição usadas no ensaio (Figura 1). Quando confrontados com os padrões coletivos descritos por Lee et al. (1998), ficou evidenciado que os padrões obtidos para as enzimas HpaII e HhaI são típicos de fitoplasmas do grupo 16SrIII. O emprego das endonucleases $A l u \mathrm{I}, R s a \mathrm{I}$ e $M b o \mathrm{I}$ confirmaram os resultados obtidos com as enzimas anteriormente referidas, revelando que o fitoplasma em estudo é afiliado ao grupo $16 \mathrm{SrIII}$ e distinto dos fitoplasmas representantes dos demais grupos $16 \mathrm{Sr}$ conhecidos. A análise de RFLP, contudo, não permitiu classificar o fitoplasma presente na abobrinha-de-moita em nível de subgrupo; no entanto, demonstrou seguramente que o fitoplasma pertence ao grupo 16SrIII, confirmando a identificação feita por PCR com os "primers" específicos.

Os sintomas observados nas plantas de abobrinhade-moita naturalmente infectadas eram indicativos da ocorrência de doença associada a fitoplasmas, sendo muito 


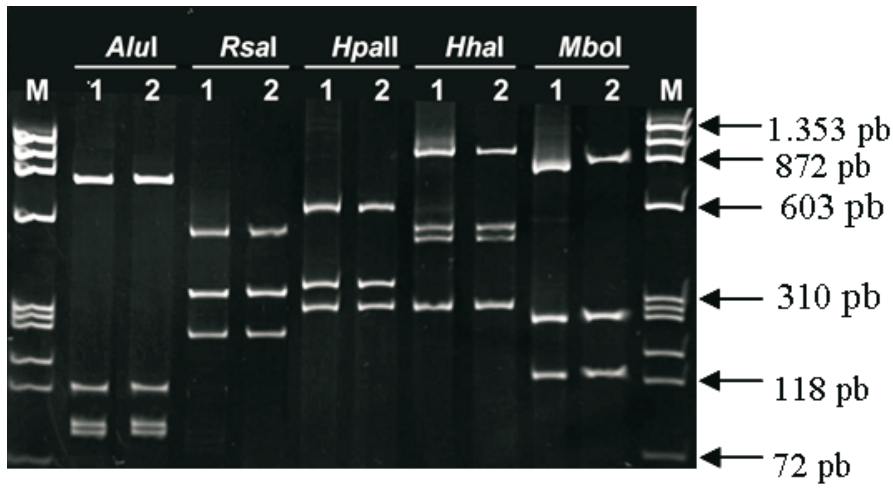

FIGURA 1 - Identificação molecular do fitoplasma detectado em amostras de tecidos doentes de abobrinhade-moita (Cucurbita pepo), por análise de RFLP com as enzimas de restrição: AluI, RsaI, HpaII, HhaI e MboI. Linha 1: fitoplasma do enfezamento da berinjela (grupo 16SrIII), usado como referência; Linha 2: fitoplasma presente em abobrinha-de-moita; Linha M: marcador de peso molecular $\phi$ X174 RF DNA HaeIII digest. semelhantes àqueles anteriormente descritos para espécies de cucurbitáceas que apresentavam anomalias típicas de amarelos (Zitter et al., 1996). Relato sobre a presença de fitoplasmas em plantas de abóbora cultivadas no Brasil foi feito, anteriormente, com amostras de C. moschata, no Rio de Janeiro (Montano et al., 2006). Os sintomas descritos para esta espécie foram similares àqueles observados nas plantas de abobrinha-de-moita, cultivadas no Vale do Ribeira (SP). A distinção entre plantas doentes e sadias era muito clara no campo e facilmente perceptível aos olhos de um observador, tanto que chamou a atenção de um produtor, o qual encaminhou amostras para diagnose. No entanto, o produtor não esperou pelos resultados da análise e, de imediato, promoveu a erradicação das plantas doentes. Isto impediu a obtenção de maiores informações sobre a doença, principalmente quanto à incidência da mesma no campo. Apesar disso, os resultados obtidos neste trabalho revelaram a associação de fitoplasma pertencente ao grupo $16 \mathrm{SrIII}$ com os sintomas de amarelos presentes em abobrinha-de-moita. A ocorrência de fitoplasmas em espécies de Cucurbita não se restringe ao grupo $16 \mathrm{SrIII}$, embora somente fitoplasmas do grupo 16SrIII tenham sido identificados até o momento no país, no Rio de Janeiro (Montano et al., 2006) e em São Paulo (presente trabalho). Em outros países, fitoplasmas pertencentes ao grupo 16 SrIII não foram ainda relatados em espécies da família Cucurbitaceae, havendo, no entanto, relatos de fitoplasmas afiliados aos grupos 16SrI na América Central e do Norte (Villalobos et al., 2002; Lee et al., 1993), 16SrVIII em Taiwan (Lee et al., 1993) e 16SrXII na Austrália (Streten et.al., 2005). Fitoplasmas pertencentes ao grupo 16SrIII têm sido também encontrados em associação com doenças de outras cucurbitáceas de ocorrência bastante comum em algumas regiões brasileiras, como o irizado ou superbrotamento do chuchuzeiro, superbrotamento do melão-de-São Caetano e superbrotamento da bucha (Montano et al., 2000, 2007a). Representantes deste grupo têm sido ainda identificados em hortaliças da família Solanaceae, como em tomateiro afetado pelo cálice gigante (Amaral-Mello et al., 2006). Dentre os fitoplasmas relatados no território brasileiro, os representantes do grupo
16SrIII têm se mostrado predominantes e aparentemente pouco específicos em relação aos hospedeiros, tendo sido constatados numa diversidade de espécies além daquelas pertencentes às famílias Cucurbitaceae e Solanaceae. Assim, existem relatos de fitoplasmas do grupo 16SrIII associados aos superbrotamentos em begônia, crotalária, mandioca, maracujá e sempre-viva; à proliferação de ramos em bicode-papagaio; ao lenho mole em maçã; ao enfezamento em repolho; ao amarelo em videira e ao amarelecimento e virescência em vinca (Montano et al., 2007b). O presente trabalho representa contribuição ao conhecimento da diversidade de fitoplasmas e de seus hospedeiros, presentes no território brasileiro, além de relatar, pela primeira vez no Brasil, a ocorrência de um fitoplasma do grupo $16 \mathrm{SrIII}$ associado ao amarelo em plantas da espécie Cucurbita pepo, popularmente conhecida como abobrinha-de-moita.

\section{REFERÊNCIAS BIBLIOGRÁFICAS}

Ahrens U, Seemüller E (1992) Detection of DNA of plant pathogenic mycoplasmalike organisms by a polymerase chain reaction that amplifies a sequence of the $16 \mathrm{~S}$ rRNA gene. Phytopathology 82:828-832.

Amaral-Mello APO, Bedendo IP, Kitajima EW, Ribeiro LFC, Kobori R (2006) Tomato big bud phytoplasma associated with a phytoplasma belonging to group 16SrIII in Brazil. International Journal of Pest Management 52:233-237.

Freitag JH (1956) Western aster yellows virus infection of squash, pumpkin, and cucumber. Phytopathology 46:323-326.

Gundersen DE, Lee IM (1996) Ultrasensitive detection of phytoplasmas by nested-PCR assays using two universal primer pairs. Phytopathologia Mediterranea 35:144-151.

Lee IM, Hammond RW, Davis RE, Gundersen DE (1993) Universal amplification and analysis of pathogen 16S rDNA for classification and identification of mycoplasmalike organisms. Phytopathology 83:834-842.

Lee IM, Gundersen DE, Hammond RW, Davis RE (1994) Use of mycoplasmalike organism (MLO) group-specific oligonucleotide 
primers for nested-PCR assays to detect mixed-MLO infections in a single host plant. Phytopathology 84:559-566.

Lee IM, Gundersen-Rindal DE, Davis RE, Bartoszyk IM (1998) Revised classification scheme of phytoplasmas based on RFLP analyses of $16 \mathrm{~S}$ rRNA and ribosomal protein gene sequences. International Journal of Systematic Bacteriology 48:1153-1169.

Montano HG, Davis RE, Dally EL, Pimentel JP, Brioso PST (2000) Identification and phylogenetic analysis of a new phytoplasma from diseased chayote in Brazil. Plant Disease 84:429-436.

Montano HG, Brioso PST, Pimentel JP, Figueiredo DV, Cunha Júnior JO (2006) Cucurbita moschata, new phytoplasma host in Brazil. Journal of Plant Pathology 88:226.

Montano HG, Brioso PST, Cunha Júnior JO, Figueiredo DV, Pimentel JP (2007a) First report of group 16SrIII phytoplasma in loofah. Bulletin of Insectology 60:277-278.

Montano HG, Brioso PST, Pimentel JP (2007b) List of phytoplasma hosts in Brazil. Bulletin of Insectology 60:129-130.
Saqib M, Jones MGK, Jones RAC (2006) 'Candidatus phytoplasma australiense' is associated with diseases of red clover and paddy melon in south-west Australia. Australasian Plant Pathology 35:283-285.

Smart CD, Schneider B, Blomquist CL, Guerra LJ, Harrison NA, Ahrens U, Lorenz KH, Seemüller E, Kirkpatrick BC (1996) Phytoplasma-specific PCR primers based on sequences of the 16S-23S rRNA spacer region. Applied and Environmental Microbiology 62:2988-2993.

Streten C, Conde B, Herrington M, Moulden J, Gibb K (2005) "Candidatus phytoplasma australiense" is associated with pumpkin yellow leaf curl disease in Queensland, Western Australia and the Northern Territory. Australasian Plant Pathology 34:103-105.

Villalobos W, Moreira L, Rivera C, Bottner KD, Lee IM (2002) First report of an aster yellows subgroup 16SrI-B phytoplasma infecting chayote in Costa Rica. Plant Disease 86:330-330.

Zitter TA, Hopkins DL, Thomas CE (Eds.) (1996) Compendium of cucurbit diseases. Saint Paul MN. APS Press. 